\title{
Effects of estrogen on the vascular system
}

\author{
R.C. Tostes, D. Nigro, \\ Z.B. Fortes and \\ M.H.C. Carvalho
}

\author{
Grupo de Pesquisa sobre Hipertensão Arterial, \\ Departamento de Farmacologia, Instituto de Ciências Biomédicas, \\ Universidade de São Paulo, São Paulo, SP, Brasil
}

\author{
Correspondence \\ M.H.C. Carvalho \\ Departamento de Farmacologia \\ ICB, USP \\ Av. Lineu Prestes, 1524 \\ 05508-900 São Paulo, SP \\ Brasil \\ Fax: +55-11-3091-7322 \\ E-mail: mhcarval@icb.usp.br \\ Research supported by PRONEX (No. \\ 125/98), FAPESP (Nos. 97/14208-8, \\ 00/04611-4, and 00/12141-8), CAPES \\ and CNPq (No. 351365/1997-4).
}

Received March 14, 2003 Accepted May 28, 2003

\begin{abstract}
The cardiovascular protective actions of estrogen are partially mediated by a direct effect on the vessel wall. Estrogen is active both on vascular smooth muscle and endothelial cells where functionally competent estrogen receptors have been identified. Estrogen administration promotes vasodilation in humans and in experimental animals, in part by stimulating prostacyclin and nitric oxide synthesis, as well as by decreasing the production of vasoconstrictor agents such as cyclooxygenase-derived products, reactive oxygen species, angiotensin II, and endothelin-1. In vitro, estrogen exerts a direct inhibitory effect on smooth muscle by activating potassium efflux and by inhibiting calcium influx. In addition, estrogen inhibits vascular smooth muscle cell proliferation. In vivo, 17ß-estradiol prevents neointimal thickening after balloon injury and also ameliorates the lesions occurring in atherosclerotic conditions. As is the case for other steroids, the effect of estrogen on the vessel wall has a rapid non-genomic component involving membrane phenomena, such as alteration of membrane ionic permeability and activation of membrane-bound enzymes, as well as the classical genomic effect involving estrogen receptor activation and gene expression.
\end{abstract}

Key words

- Sex hormones

- Estrogen

- Vascular smooth muscle

- Endothelium, nitric oxide

- Endothelium-derived

hyperpolarizing factor

- Angiotensin

- Endothelin-1

- Calcium channels

- Potassium channels

\section{Introduction}

Extensive epidemiological observations, clinical mechanistic studies, and basic laboratory research have suggested that the incidence of cardiovascular disease increases with menopause and that hormone replacement therapy, or more specifically, estrogen replacement therapy is associated with beneficial cardiovascular effects in postmenopausal women $(1,2)$. Estrogen has a multitude of biological effects that may account for its apparent cardiovascular benefits (which remain to be proved in randomized clinical trials), including favorable effects on the lipid profile, antioxidant activity, en- hanced fibrinolysis, and a series of actions on the vasculature, which will be the focus of our review. Since selective estrogen receptor modulators (SERMs), such as the synthetic estrogen-like compounds tamoxifen and raloxifene, are being considered as an option in hormone replacement therapy due to their estrogen-agonist effects on some tissues (liver, bone) and estrogen-antagonistic effects on other tissues (breast, uterus), we included some of the already described vascular effects of SERMs in this review.

\section{Effects of estrogen}

The actions of steroid hormones can be 
divided into two types: those that are delayed in onset and prolonged in duration are called "genomic" effects, and those that are rapid in onset and short in duration are called "non-genomic" effects. The early effects take place within minutes (e.g., changes in vasomotor tone) and are mediated by rapid intracellular signaling pathways, whereas the delayed effects (e.g., remodeling or lipid alterations) require hours to days to occur and require transcriptional events with subsequent modulation of protein expression. Although the rapid and delayed effects of steroids are clearly distinguishable from each other, there are actions that have onset time of minutes and it is not clear as to whether genomic or non-genomic mechanisms apply.

\section{Estrogen receptors and mechanisms of action}

Radioactive estrogens (tritium-labeled estrogens) were used to demonstrate for the first time intracellular steroid hormone receptors in endocrine target organs through the body. Later, cells expressing the genomic steroid receptors were identified and mapped by binding studies, by immunocytochemistry, and by in situ hybridization. The receptors for estrogen and for all classes of steroidal hormones (androgens, glucocorticoids, mineralocorticoids, progestins, vitamin D), as well as thyroid hormones and retinoic acid, belong to the class of intracellular receptors and have been classically defined as nuclear ligand-activated transcription factors. Activation of these receptors by the corresponding hormones affects gene expression by acting on specific sequences in the target genes, known as estrogen-response elements, and by modulating transcriptional events. Importantly, gene expression may be further regulated through positive and negative interactions of estrogen receptors (ER) with transcription factors (3). The discovery of intracellular hormone receptors led to studies focusing on the long- lasting effects of steroids (genomic effects) on cell function. However, the fact that not all actions of estrogens are delayed in onset and prolonged in duration implies another mechanism of action (non-genomic effects). Some of the estrogen effects are mediated by ERs localized on the cell surface since membrane-impermeant forms of estrogen lead to the activation of mitogen-activated protein kinase (MAPK) as well as stimulation of cGMP production and nitric oxide (NO) release. The use of confocal microscopy and flow cytometric analysis has demonstrated that endothelial cells contain surface receptors for estrogen, detectable by cell-impermeant ligand binding and anti-ER antibodies. Activation of membrane ERs has been linked to novel, rapid signaling pathways induced by estrogen. More recently, it was shown that several actions of steroid hormones on membranes involve non-nuclear signaling pathways, such as coupling to $G$ proteins and generation of second messengers (4). Estrogens can induce $\mathrm{Ca}^{2+}$ mobilization, increase levels of cyclic nucleotide second messengers, and activate several kinases, including protein kinase $\mathrm{C}$, phosphatidylinositol-3-OH kinase (PI3-kinase), and MAPK through incompletely defined mechanisms $(5,6)$. Adding more complexity, non-genomic effects of steroid hormones may be receptor-mediated or receptor-independent. Steroid hormone genomic and non-genomic effects may occur simultaneously and may act at different levels, revealing the high complexity of steroid hormone regulation of cell function.

The original studies indicated that there was one type of steroid receptors and that the nature of the biological responses in different tissues was determined by the network of genes available for interaction with the activated receptor. Later, two independent groups cloned the ER complementary DNA $(7,8)$.

However, the distribution of this ER could not explain all of the biological effects of estrogens, for instance in the ovaries. Later, 
when a second ER was cloned, a useful explanation for the dissociation between the ER localization and effects of estrogen was suggested (9). Two types of intracellular ERs have been identified: ER- $\alpha$ and ER- $\beta$, and isoforms of ER- $\alpha$ and ER- $\beta$ (splice variants ER- $\beta 1$ and ER-B2) have been also identified.

The ligand-binding domain of ER- $\beta$ shows great homology compared with that of ER- $\alpha$. High homology is also observed in the DNA-binding domain or estrogen-response element sites for the ER- $\alpha$ and ER- $\beta$ in the estrogen-sensitive genes. However, the ER domains responsible for the interaction of ER- $\alpha$ and ER- $\beta$ with transcription factors, the ligand-independent $\mathrm{N}$ - and $\mathrm{C}$ terminal transcription activation functions- 1 and -2 , markedly differ between ER- $\alpha$ and ER-ß. This lack of homology may explain the different effects on an estrogen-response element site observed with estrogen agonists and antagonists.

Furthermore, different ligands cause different conformational changes in ERs, thereby affecting interaction patterns with additional transcription factor co-regulators and eventually the fine control of gene expression. It should also be mentioned that steroid receptor co-regulators react differently with ER- $\alpha$ and ER- $\beta$. For instance, the two ERs interact with an activator protein-1 site in opposite ways in the presence of different ligands (10). Finally, recent work indicated that ER- $\beta$ may counteract or control ER- $\alpha$ activity in a variety of tissues, including the uterus, and mediate estrogenic effects other than ER- $\alpha$ in some tissues, such as the bone or the immune system.

The discovery and cloning of ER- $\beta$ provided a basis for understanding how the knockout of ER- $\alpha$ could have resulted in a viable organism and in the continued action of estrogens in some tissues, although animals are sterile and show altered sexual and other behaviors (11). On the other hand, knockout mice for ER-ß appear quite normal and are able to reproduce, although they show some reduction in litter size (12).

Measurements of mRNA for ER- $\alpha$ and ER- $\beta$ have shown distributions in the body that differ quite markedly from each other. Moderate to high expression of ER- $\alpha$ has been identified in the pituitary, kidney, epididymis, and adrenal glands, whereas moderate to high expression of ER- $\beta$ has been found in prostate, lung, bladder, and brain. Overlapping high expression of ER- $\alpha$ and ER- $\beta$ has been identified in ovary, testis and uterus. In the vasculature, ERs have been identified by different techniques in the endothelium, intima and adventitia and on adrenergic nerve endings of arteries from various territories and several species, including humans.

A very interesting observation is that the vascular cells are capable of expressing aromatase, the key enzyme in the estrogen synthesis pathway, suggesting that the vascular system is capable of local estrogen biosynthesis in vivo, which may lead to activation of ER and downstream activation of target genes (13). Locally produced estrogen may therefore act in an endocrine, paracrine and autocrine manner on vascular and nonvascular cells.

\section{Effects of estrogen on the arterial wall}

Actions of steroidal hormones on the arterial wall include alteration or modulation of ion fluxes and of receptors on smooth muscle cells and modulation of endothelium-derived factor production and activity. In this review we focused on the effects of estrogen on components of endothelial and smooth muscle cells. However, it is important to keep in mind that estrogen-induced effects depend on the vascular bed and on the animal species being considered, indicating that there is regional and species heterogeneity in the modulatory influence of estrogen on vasomotor function. To mention 
few examples, it has been reported that $17 \beta$ estradiol induces both endothelium-dependent and -independent relaxation in the rat aorta but only endothelium-independent relaxation in the rat mesenteric arteries. NO contributes strongly to the endotheliumdependent relaxation induced by $17 ß$-estradiol in isolated aortas, whereas in small cerebral arteries both NO and cyclooxygenase (COX) metabolites contribute to estrogeninduced effects. Estrogen treatment increases aortic stiffness and potentiates endothelial vasodilator function in the hindquarters, but not in the carotid vascular bed. Differences in the mechanisms involved in estrogen actions may reflect a differential contribution of mechanisms involved in vascular tone regulation. Furthermore, there is evidence that ER expression may change with pathological conditions or, inversely, that changes in ER expression may lead to abnormal vascular function (14).

\section{Actions of estrogen on endothelial cells}

The endothelium plays a major role in vascular tone control by releasing both relaxing and contractile factors and estrogens exert a number of effects on endothelialderived factors, as summarized below.

Estrogens have been shown to enhance endothelial-dependent relaxation in arterial rings from different animals and from different vascular beds, including coronary, mesenteric, aorta and cerebral arteries. Studies on humans have demonstrated that estrogen replacement treatment increases coronary flow and decreases both coronary resistance and peripheral vascular tone.

\section{Nitric oxide}

Earlier reports indicated that basal release of NO is increased in females compared to males $(15,16)$ and that estrogen administration to ovariectomized rats restores the impaired ex vivo basal release of NO. Effects of estradiol were also described in arteries from male animals. Huang et al. (17) observed that $17 \AA$-estradiol restores endothelial NO release in response to shear stress in pressurized gracilis muscle arterioles of male spontaneously hypertensive rats (SHR) by up-regulation of endothelial nitric oxide synthase (NOS). Conversely, it has been reported that endothelium-dependent relaxation elicited by carbachol and histamine was attenuated by estradiol in preparations from intact male rats. Moreover, aortic prostacyclin release was reduced by about $40 \%$ after estradiol treatment in tissues from these animals. These results showing that release of $\mathrm{NO}$ in arteries from male rats is not affected by estradiol treatment suggest gender specificity for the vascular effects of estrogen.

NO production accounts for most of the endothelium-dependent relaxation activity, and there is extensive evidence showing estrogen-induced up-regulation of endothelial NO production. Probable mechanisms involved in estradiol-induced increased NO production include: 1) transcriptional stimulation of NOS gene expression, 2) inhibition of cytokine-induced down-regulation of NOS gene expression, 3) post-translational modification of NOS protein, 4) increased cofactor or L-arginine availability, 5) non-genomic activation of second messengers (e.g., $\mathrm{Ca}^{2+}, \mathrm{cAMP}$ ) and tyrosine kinase, 6) translocation from the membrane to intracellular sites, and 7) modulation of NO degrading systems (e.g., reactive oxygen radical generation and antioxidants).

Induction of constitutive $\left(\mathrm{Ca}^{2+}\right.$-dependent) NOS by estrogen has been demonstrated in a variety of tissues, consistent with the presence of estrogen-response elements in the NOS promoter. In addition to increasing NOS production, estrogen induces rapid enhancement of NOS activity and NO release through nontranscriptional mechanisms and by reducing its $\mathrm{Ca}^{2+}$ dependence (18). This 
effect seems to be much more intense and functionally relevant than the increase in NOS expression induced by estrogen and is inhibited by the ER antagonist ICI 182,780, indicating that the effect is mediated by ERs (19). In SHR, estrogen deprivation (induced by ovariectomy) decreases NOS activity and expression and NO-derived metabolites (20).

Recent studies indicate that estrogen-induced activation of endothelial NOS is driven by activation of the PI3-kinase/Akt pathway resulting from direct interactions between the ER and the regulatory subunit of PI3kinase (6), and requires MAPK activation (19). Hisamoto et al. (21) observed that 17ßestradiol, but not $17 \alpha$-estradiol, caused acute activation of endothelial NOS both in human umbilical vein endothelial cells and in simian virus 40-transformed rat lung vascular endothelial cells. Activation of endothelial NOS involves the activation of Akt and the phosphorylation of endothelial NOS, which is mediated by ER- $\alpha$ via a non-genomic mechanism.

The effects of estrogen on NOS may also be associated with its effects on caveolin-1 expression, which inhibits endothelial NOS catalytic activity. Jayachandran et al. (22) have shown that endothelial NOS protein expression and nitrite/nitrate production by bovine aortic endothelial cells are enhanced by $17 ß$-estradiol, which also stimulates caveolin-1 transcription and translation through ER-mediated mechanisms.

Similar to estrogen, the SERM raloxifene stimulates endothelial NOS mRNA expression (genomic effects) and also triggers rapid activation of NO synthesis by stimulating endothelial NOS (non-genomic effects) via the PI3-kinase pathway ER signaling (23). In femoral veins, raloxifene induces acute relaxation both by NO release and by direct stimulation of vascular smooth muscle cells depending on the ovarian hormonal status of the animal. As we will discuss later, estrogen also prevents NO degradation due to its antioxidant properties, consequently increasing
NO availability.

The effects of estrogen on NOS activity are suggested to be important in arterial injury. Local delivery of 17ß-estradiol during percutaneous transluminal coronary angioplasty improved endothelial function, enhanced re-endothelialization and endothelial NOS expression and decreased neointima formation. Recently, Tolbert et al. (24) have shown that the vasoprotective effects of estrogen after ligation vascular injury are partially reduced in inducible NOS knockout mice, suggesting that estrogen also modulates inducible NOS expression and plays a role in neointima formation.

\section{Endothelium-derived hyperpolarizing factor}

Endothelium-derived hyperpolarizing factors (EDHFs) are important mediators of vascular relaxation, more specifically in resistance-sized arteries where they regulate tissue blood flow. The release of EDHFs is modulated by a number of influences including agonist stimulation, shear stress, and disease. The chemical identification and functional characterization of EDHFs vary depending on vascular size, vascular bed and species. Three major candidates are the epoxyeicosatrienoic acids, cytochrome $\mathrm{P} 450$ metabolites of arachidonic acid, $\mathrm{K}^{+}$and hydrogen peroxide. Additionally, electrical coupling through myoendothelial gap junctions serves to conduct electrical changes from the endothelium to the smooth muscle and may mediate or propagate hyperpolarization.

Evidence showing that estrogen modulates EDHF production and release has accumulated over the past few years. One of the first lines of evidence for estrogen-induced hyperpolarization, although not specifically by EDHF, was provided by Harder and Coulson (25). They observed that addition of diethylstilbestrol to dog coronary arteries hyperpolarized the membrane and reduced input resistance, which was not related to 
increased $\mathrm{Na}^{+}-\mathrm{K}^{+}$ATPase pump activity.

Later, it was shown that the hyperpolarizing response to acetylcholine in mesenteric arteries isolated from middle-aged rats is significantly greater in females than in males. Ovariectomy causes a marked reduction in acetylcholine-induced hyperpolarization in female arteries and this is improved by 178 estradiol replacement therapy (26). Further evidence for a positive modulation of EDHF release by estrogen is provided by the observation that during pregnancy, a condition with high levels of estrogen, there is an upregulation of EDHF-mediated vasodilation. On the other hand, in pial arteries from female rats, ovariectomy increases the NOand prostacyclin $\left(\mathrm{PGI}_{2}\right)$-insensitive dilation (EDHF-mediated dilation) whereas estradiol replacement reduces it, suggesting a negative modulation of estrogen on EDHF release.

\section{Arachidonic acid metabolites}

The actions of estrogen on vascular cells also influence the metabolism of prostaglandins and the activity of COX, a key enzyme in the production of prostaglandins.

It has been repeatedly shown that $178-$ estradiol stimulates production of vasodilator prostaglandins such as $\mathrm{PGI}_{2}$ in a variety of preparations such as ovine uterine arteries, ovine fetal pulmonary artery endothelial cells, human umbilical vein endothelial cells, and rat mesenteric and cerebral blood vessels.

Increased levels of $\mathrm{PGI}_{2}$ upon stimulation with estradiol have been associated with increased expression of the key enzymes involved in $\mathrm{PGI}_{2}$ production, phospholipase $\mathrm{A}_{2}, \mathrm{COX}-1$, and prostacyclin synthetase (PGIS), as demonstrated in rat cerebral blood vessels, where chronic in vivo $17 \beta$-estradiol treatment enhances basal $\mathrm{PGI}_{2}$ synthesis by increasing COX-1 and PGIS proteins (27). It seems that the COX-2 pathway also plays a specific role in estradiol-induced $\mathrm{PGI}_{2}$ synthesis and vasodilation. In human umbilical vein endothelial cells, 17ß-estradiol increases the release of $\mathrm{PGI}_{2}$ via the induction of $\mathrm{COX}$ 2 , but not COX-1 protein (28), and in the cutaneous vasculature of postmenopausal women, acute 17ß-estradiol administration enhanced the response to acetylcholine after aspirin, diclofenac, and placebo, but not after celecoxib treatment (29).

More recently, an association between estradiol and vasoconstrictor prostaglandins has also been established: 1) estrogen replacement prevents prostaglandin $\mathrm{H}$ synthase (PGHS)-dependent vasoconstriction, that was associated with augmented sensitivity of the thromboxane $\mathrm{A}_{2}\left(\mathrm{TXA}_{2}\right)$ /prostaglandin $\mathrm{H}_{2}\left(\mathrm{PGH}_{2}\right)$ receptor, in resistance-sized mesenteric arteries from ovariectomized Sprague-Dawley rats, 2) estrogen improves vasodilation in isolated mesenteric arteries from aged Fisher rats by decreasing PGHS2-dependent constriction and PGHS-2 expression, and 3) estrogen decreases the synthesis of contractile COX metabolites. We have shown that ovariectomy increases reactivity to norepinephrine and reduces sensitivity to acetylcholine in microvessels from SHR whereas treatment with estradiol or estradiol + progesterone similarly restored these altered responses. The COX inhibitors indomethacin, diclofenac, as well as ridogrel (a $\mathrm{TXA}_{2}$ receptor antagonist and inhibitor of thromboxane synthase), but not dazoxiben (an inhibitor of thromboxane synthase), also restored norepinephrine and acetylcholine responses in ovariectomized SHR. The release of $\mathrm{PGF}_{2} \alpha$, but not of $\mathrm{TXB}_{2}$ and 6-keto$\mathrm{PGF}_{1} \alpha$, was greater in ovariectomized SHR than in control SHR microvessels upon stimulation with norepinephrine, suggesting that estrogen decreases the synthesis of contractile COX metabolites, such as $\mathrm{PGH}_{2} / \mathrm{PGF}_{2} \alpha$ (30).

As mentioned earlier, not all arteries respond in the same way to estradiol. It has been reported that estradiol and progesterone treatments differentially alter protein expression of the key enzymes involved in $\mathrm{PGI}_{2}$ production, phospholipase $\mathrm{A}_{2}, \mathrm{COX}-1$, 
and PGIS, in uterine and systemic (renal, coronary, mammary, omental) arteries.

The modulatory actions of estrogen on the COX pathway seem to be mediated through activation of ERs. In pulmonary artery endothelial cells, $\mathrm{PGI}_{2}$ production is mediated by ER- $\beta$, since it was fully blocked by both ER antagonism with ICI 182,780, which is not selective for either ER isoform, and the ER- $\beta$-specific antagonist RRtetrahydrochrysene. On the other hand, the observation that estrogen increases COX-1 levels in cerebral blood vessels from wildtype mice, but is ineffective in ER- $\alpha$ knockout mice, suggests that ER- $\alpha$ regulation of the endothelial COX-1 pathway also appears to contribute to the effects of estrogen.

\section{Adhesion molecules}

In an inflammatory process, cytokines and other inflammatory mediators elicit remarkable phenotypic changes in endothelial cells. Activated endothelial cells release NO and $\mathrm{PGI}_{2}$, leading to vasodilation, which in turn facilitates leukocyte influx to the sites of injury. Cytokine-activated endothelial cells express adhesion molecules for leukocytes E-selectin, intercellular adhesion molecule1 (ICAM-1) and vascular cell adhesion molecule-1 (VCAM-1) - and are a source of chemokines that not only have chemotactic effects on leukocytes, but also are potent activators of leukocyte integrins, allowing their interaction with their endothelial counterreceptors.

Many cell types involved in immune and inflammatory responses are responsive to estrogen. These include $\mathrm{T}$ and $\mathrm{B}$ lymphocytes, and cells from the myelomonocytic lineage such as monocytes, macrophages, and mast cells. Actions of estrogen on inflammatory markers seem to depend on levels of estrogen. At physiological concentrations, estrogen increases proinflammatory cytokine production - IL-1, tumor necrosis factor- $\alpha$ (TNF- $\alpha)$, and IL- 6 - by monocytes.
However, subjects with high estrogen status (premenopausal women) have significantly lower monocyte chemoattractant protein (MCP-1) levels than subjects with low estrogen status (postmenopausal women), and hormone replacement therapy lowers plasma levels of MCP-1 (31). The estrogen-induced increase in TNF- $\alpha$ activates endothelial adhesion to leukocytes via increased expression of the endothelial adhesion molecules E-selectin, ICAM-1, and VCAM-1 (32). Kinetic studies of mRNA for endothelial adhesion molecules show that, at early time points, estrogen treatment results in increased levels of mRNA for E-selectin, ICAM-1, and VCAM-1, whereas at later time points, estrogen-treated cells disclose lower levels of mRNA for these cytokines (32).

However, at higher or pharmacological doses and after longer periods of exposure, estrogen decreases cytokine-induced adhesion molecule expression by cultured endothelial cells (33). A prospective, randomized, placebo-controlled 12-week study on healthy, normotensive postmenopausal women who received either micronized estradiol alone, or sequentially estradiol combined with a progestagen showed a significant decrease in the plasma concentrations of soluble ICAM-1, soluble VCAM-1, and thrombomodulin. In the same direction, it has been shown that Fas ligand expression by the vascular endothelium, which inhibits the migration of inflammatory cells into the vessel wall, is improved by estradiol treatment, resulting in inhibition of leukocyte traffic across the endothelium. According to the authors, the maintenance of endothelial Fas ligand expression by estradiol may represent a mechanism of the apparent antiatherogenic effect of estrogen.

\section{Oxidative stress - reactive oxygen species}

The vasculoprotective effects of estrogen have been also partially attributed to a shift in the $\mathrm{NO} /$ superoxide anion $\left(\mathrm{O}_{2}^{-}\right)$bal- 
ance in the vessel wall, thereby increasing the bioavailability of NO. In human umbilical vein cultured endothelial cells, 17ß-estradiol decreases expression of the NADPH oxidase subunit gp91phox and up-regulates endothelial NOS expression, improving the $\mathrm{NO} / \mathrm{O}_{2}^{-}$balance (34). On the other hand, estradiol increases endothelium-derived relaxing factor activity in the thoracic aorta of ovariectomized female rats in the absence of changes in NOS activity or NOS gene and protein expression. Since lucigenin-enhanced chemiluminescence, an indicator of $\mathrm{O}_{2}^{-}$production, of the aorta was decreased in estradiol-treated ovariectomized rats compared to the placebo group, it was suggested that the decreased endothelium-derived generation of $\mathrm{O}_{2}{ }^{-}$in response to estrogens accounts for enhanced NO bioactivity and decreased peroxynitrite release (35). Increased oxidative stress and decreased $\mathrm{NO}$ production due to estrogen deficiency have been associated with higher blood pressure levels. Chronic estrogen replacement in ovariectomized rats prevents the decrease of plasma levels of nitrites/nitrates as well as the enhancement of blood pressure.

Wassmann et al. (36) observed that estrogen replacement therapy and angiotensin type 1 (AT1) receptor antagonism prevent the worsened endothelial dysfunction, enhanced vasoconstrictor response to angiotensin II (Ang II) and increased vascular $\mathrm{O}_{2}{ }^{-}$production displayed by ovariectomized SHR. Very recently, it has been shown that estrogen reduces Ang II-induced expression of $\mathrm{NAD}(\mathrm{P}) \mathrm{H}$ oxidase and peroxynitrite in cultured endothelial cells. Estrogen as well as superoxide dismutase also inhibited Ang II-induced AT1 receptor expression and nitrotyrosine staining, effects that were not inhibited by the ER antagonist ICI 182,780 (37).

We have shown that treatment with superoxide dismutase also restored changes in norepinephrine and acetylcholine responses in ovariectomized SHR (38). We have also found evidence that estrogen reduces $\mathrm{O}_{2}{ }^{-}$ bioavailability in SHR microvessels in vivo. We observed that oxidative stress in mesenteric arteries, evaluated by using intravital microscopy and superfusion with hydroethidine, was significantly increased in ovariectomized SHR and was attenuated by estradiol or estradiol + progesterone treatment. Treatment with the superoxide dismutase mimetic MnTMPyP, but not with mannitol, that decomposes hydroxyl radicals, or LNAME, an NOS inhibitor, attenuated oxidative stress in ovariectomized SHR. Treatment of mesenteries with diphenyleneiodonium, an $\mathrm{NAD}(\mathrm{P}) \mathrm{H}$ oxidase inhibitor, but not with oxypurinol, a xanthine oxidase inhibitor, produced a significant reduction of oxyradical generation in microvessels from ovariectomized SHR (38).

Similar to estrogen, the SERM idoxifene effectively blunts Ang II-induced reactive oxygen species production as evaluated by confocal laserscanning microscopy using the redox sensitive marker 2',7'-dichlorofluorescein and measurement of NAD(P)H oxidase activity. This estrogen effect has been explained in part by idoxifene-induced downregulation of AT1 receptor expression, as will be discussed later.

The estrogen-mediated induction of the protein thiol/disulfide oxidoreductases such as disulfide isomerase, thioredoxin, thioredoxin reductase, and glutaredoxin in vascular endothelial cells may also be involved in the antioxidant properties of estrogen observed in the vascular system. Recent studies have also shown that estrogen inhibits endothelial cell apoptosis induced by hydrogen peroxide and that phytoestrogens (daidzein, genistein and resveratrol) attenuate the oxidative DNA damage induced by advanced glycation end-products in vascular smooth muscle cells. The latter action was associated with an increase in intracellular total glutathione levels.

In humans it has been suggested that the endothelial dysfunction secondary to acute endogenous estrogen deprivation (surgical 
ovariectomy) is caused by reduced NO availability, which results from COX-dependent production of oxidative stress (39).

\section{Angiotensin II}

Estrogen acts on the renin-angiotensin system at different points of the cascade: at the formation of Ang II, at the level of Ang II receptors and on Ang II-induced responses.

Estrogen has been shown to increase gene expression and plasma levels of angiotensinogen. Estrogen also has effects on the levels of renin in the circulation: 1) women under hormone replacement therapy with estrogen display lower renin levels than those not using such therapy, 2) premenopausal women display lower renin levels than postmenopausal women, and 3) women display lower renin levels than men.

Estrogen deficiency has been shown to increase the subtype 1 Ang II receptor (AT1 receptor) mRNA levels, as well as the efficacy of Ang II on vasoconstriction (due to increased AT1 receptor density), whereas estrogen replacement therapy in ovariectomized rats reversed AT1 receptor overexpression. Down-regulation of AT1 receptor mRNA and protein expression by estrogen occurs through activation of ERs and seems to be mediated by NO-dependent pathways (40).

Estrogen treatment also antagonizes the AT1 receptor-mediated growth-promoting effects of Ang II in vascular smooth muscle cells and the mechanisms involved in the action of 17ß-estradiol include attenuation of AT1 receptor-mediated extracellular signal-regulated kinase activation and transactivation of MAPK phosphatase-1 expression (41).

As mentioned earlier, estrogen and SERMs, such as idoxifene, inhibit Ang IIinduced reactive oxygen species release. Our group has observed that chronic treatment of female SHR with losartan caused similar decreases in oxyradicals in both control and ovariectomized rats, whereas diclofenac and verapamil had no effects (38), suggesting that, despite the contribution of Ang II to the oxidative stress in SHR, this is not the pathway that is up-regulated in the absence of estrogen.

The action of estrogens on angiotensinconverting enzyme (ACE) activity have also been reported. Brosnihan et al. (42) showed that ACE activity in the circulation and in tissues is reduced upon chronic hormone replacement in two animal models of postmenopause. Reduced tissue levels (kidney and aorta) of ACE, paralleled by reduced ACE mRNA concentrations, has also been described with chronic estrogen replacement therapy.

These authors also investigated the cardiovascular responses to administration of Ang-(1-7) and Ang II in female transgenic (mRen2)27 rats receiving estrogen replacement. The estrogen-treated rats showed lower blood pressure levels and the magnitude of the depressor component of the biphasic response to Ang-(1-7) was significantly enhanced, whereas the pressor component was attenuated. Estrogen replacement also significantly attenuated the pressor response to Ang II. In addition, estrogen replacement therapy was shown to reduce plasma and tissue ACE activity in association with a reduction in circulating levels of Ang II. Because estrogen increased the levels of plasma Ang-(1-7) and amplified the vasodilator actions of Ang-(1-7), while reducing the formation and vasoconstricting actions of Ang II, the authors suggested that estrogen shifts the vasoconstrictor-vasodilator balance of the renin-angiotensin system (42).

The same group later showed that ovariectomized monkeys treated with conjugated equine estrogen replacement for 30 months exhibited a reduction of ACE activity in association with a significant increase in plasma Ang I and hyperreninemia. Plasma Ang II levels were not increased in monkeys treated with estrogen, suggesting that the 
decrease in ACE curtailed the formation of the peptide. The Ang II/Ang I ratio, an in vivo index of ACE activity, was significantly reduced by estrogen treatment, further supporting the biochemical significance of ACE inhibition by estrogen.

Clinical data have shown that postmenopausal women who received conjugated equine estrogen for 3 months exhibited a significant reduction in plasma ACE activity that correlated with an increase in NO-mediated forearm endothelium-dependent vasodilatation (reactive hyperemia) and increased serum levels of nitrite/nitrate. However, other investigators have observed that acute administration of estradiol produces no changes in vascular ACE activity or in the vasoconstricting responses to Ang I or Ang II.

Sex-related differences in the effects of blockers of the renin-angiotensin system have been documented, with female animals displaying a better response. Treatment with losartan, an AT1 antagonist, normalizes high blood pressure in $100 \%$ of female SHR against 53\% of male SHR (43). Enalapril, an ACE inhibitor, produced similar results, normalizing blood pressure in $71 \%$ of female SHR vs $46 \%$ of male SHR (44).

\section{Endothelin}

Similar to its actions on the renin-angiotensin system, the actions of estrogen on the endothelin-1 (ET-1) pathway have been shown at different points of the cascade: at its formation, at the level of the receptors and on ET-1-induced responses.

It has been reported that $17 ß$-estradiol attenuates ET-1-induced coronary artery constriction both in vitro and in vivo. In addition, increased expression of prepro-ET-1 mRNA has been observed in porcine aortic endothelial cells in the absence of female ovarian hormones. Barber et al. (45) reported that endogenous fluctuations in estrogen influence the affinity of ET-1 receptors in coronary arterial smooth muscle from fe- male pigs, and gender differences in ET-1 receptor density, as well as in the ratio of ET1 receptor subtypes, have also been reported. An increase in the total number of ET-1 receptors, but not in ET-1 binding $\mathrm{Kd}$, has been reported in human saphenous vein from men compared to women. Furthermore, a differential ratio of $\mathrm{ET}_{\mathrm{A}}$ to $\mathrm{ET}_{\mathrm{B}}$ receptors, favoring vasodilator effects in women, has also been described (46).

Our group showed that arteries from male, but not female, DOCA-salt rats display increased sensitivity to ET-1 and to the selective $\mathrm{ET}_{\mathrm{B}}$ receptor agonist IRL-1620 both in vitro and in vivo $(47,48)$. Changes in $\mathrm{ET}_{\mathrm{B}^{-}}$ mediated vascular responses were associated with increased ET-1 and ET $_{\mathrm{B}}$ receptor gene expression in male, but not in female, animals (49). Furthermore, we observed that ovariectomy increases the vasoconstricting responses to the $\mathrm{ET}_{\mathrm{B}}$ agonist and that estrogen replacement therapy restores IRL-1620induced responses, supporting our suggestion that the ovarian hormones modulate ET-1/ $\mathrm{ET}_{\mathrm{B}}$ receptor vascular responses/expression in DOCA-salt hypertension (50). Sexual dimorphism in vascular reactivity to ET-1 was also reported in SHR (51).

Estradiol, as well as 2-hydroxyestradiol, or 2-methoxyestradiol, metabolites of estradiol with little or no affinity for ERs, inhibited basal and ET-1-stimulated synthesis in porcine coronary artery endothelial cells. Estradiol-induced inhibition of ET-1 is possibly mediated by inhibition of MAPK activity, and by an ER-independent mechanism (52). On the other hand, the inhibitory effects of ICI 182,780 on the $17 ß$-estradiolinduced decrease of ET-1 gene expression and peptide secretion in cultured bovine carotid arterial endothelial cells suggest activation of ER-dependent mechanisms.

Studies conducted on healthy postmenopausal women who received continuous hormone replacement therapy (17ß-estradiol combined with norethisterone acetate or methoxyprogesterone) reported that post- 
menopausal women treated with hormone replacement therapy had increased plasma nitrites/nitrates and decreased ET-1 levels (53). Women receiving the SERM raloxifene had similar changes in plasma nitrites/nitrates and ET-1 levels as well as in the ratio of NO to ET-1 (53).

\section{Actions of estrogen on vascular smooth muscle cells}

We so far have seen that by acting on endothelial cells and modulating endothelium-derived relaxing and contraction factor release/activity, estrogen indirectly affects smooth muscle cell tone (Figure 1). Estrogen has also direct effects on smooth muscle cells. Here we will try to summarize a series of observations showing that 17ß-estradiol may play a role in selectively regulating vascular smooth muscle tone by modulating/ modifying ion channel permeability in these cells (Figure 1). The voltage-clamp technique has helped elucidate the effects of estrogen on ion channels.

\section{Potassium channels}

The actions of estradiol on $\mathrm{K}^{+}$channels have been described both in smooth muscle and endothelial cells. ATP-sensitive $\mathrm{K}^{+}$ $\left(\mathrm{K}_{\mathrm{ATP}}\right)$ channels seem to be involved in diethylstilbestrol-induced relaxation in isolated rat aorta, since diethylstilbestrol-induced vasodilation is inhibited by glibenclamide and tetraethylammonium, but not by paxillin. Since relaxation in response to forskolin was antagonized by glibenclamide, it was suggested that diethylstilbestrol-induced relaxation in the rat aorta is related to the modulation of $\mathrm{K}_{\mathrm{ATP}}$ channels via cyclic AMP-dependent mechanisms (54).

Functional studies also demonstrated that 17ß-estradiol relaxes porcine coronary arteries by an endothelium-independent mechanism involving $\mathrm{K}^{+}$efflux, and subsequent studies employing the patch-clamp technique have confirmed that estrogen stimulates $\mathrm{K}^{+}$ channel gating in coronary smooth muscle. Perforated-patch recordings from metabolically intact coronary myocytes revealed that 17ß-estradiol more than doubles steady-state outward currents in these cells at positive voltages whereas studies of on-cell patches demonstrated a potent stimulatory effect of $17 ß$-estradiol on the gating of the large-conductance, $\mathrm{Ca}^{2+}$ - and voltage-activated $\mathrm{K}^{+}$ (BKCa) channels. Furthermore, blocking BKCa channels in intact arteries inhibited estrogen-induced relaxation. Since the effect of 17ß-estradiol on BKCa channels was blocked by inhibiting cGMP-dependent protein kinase activity and was mimicked by

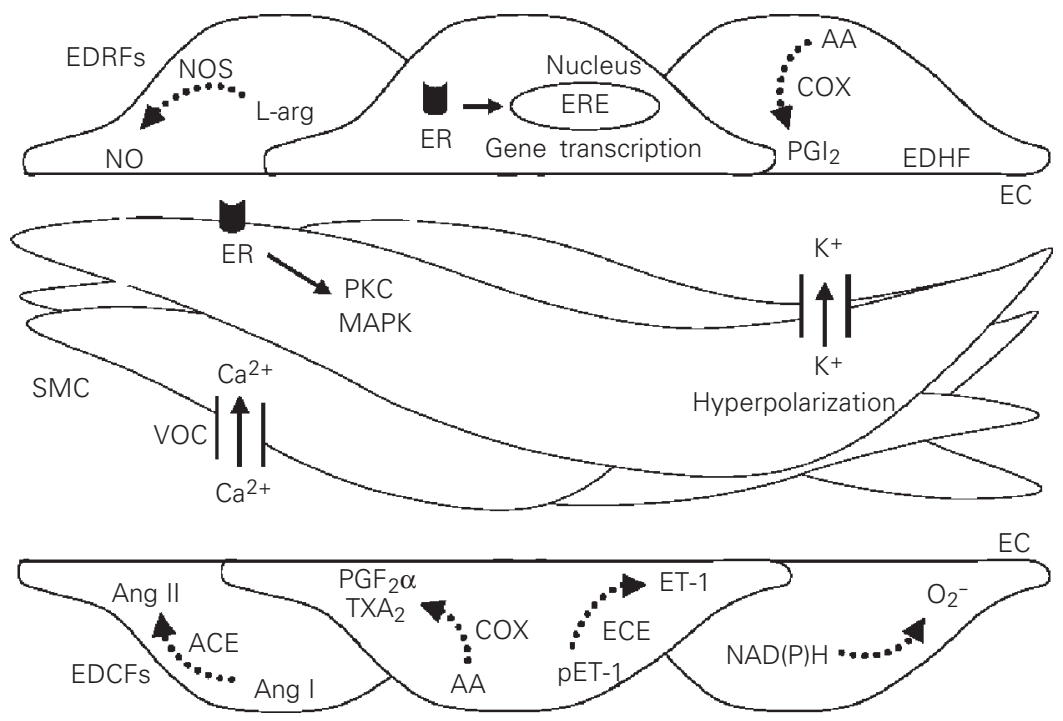

Figure 1. Putative mechanisms for the action of estrogen on the vascular system. By acting on endothelial cells, estrogen increases EDRFs (NO, EDHF and $\mathrm{PGI}_{2}$ ) production/release and decreases release/actions of EDCFs $\left(\mathrm{PGF}_{2} \alpha, \mathrm{TXA}_{2}\right.$, Ang II, ET-1, $\left.\mathrm{O}_{2}^{-}\right)$. By acting on vascular smooth muscle cells, estrogen activates $\mathrm{K}^{+}$channels, leading to cell hyperpolarization, and blocks activation of $\mathrm{Ca}^{2+}$ channels, decreasing intracellular $\mathrm{Ca}^{2+}$ concentration. Actions of estrogen may be mediated by both direct genomic effects (activation of nuclear receptors and transcriptional events) and non-genomic effects (activation of rapid intracellular signaling pathways). $\mathrm{AA}=$ arachidonic acid; $\mathrm{ACE}=$ angiotensin-converting enzyme; $\mathrm{Ang}$ $\mathrm{I}=$ angiotensin $\mathrm{I}$; Ang $\mathrm{I}=$ angiotensin $\mathrm{I} ; \mathrm{Ca}^{2+}$ channels = calcium channels; $\mathrm{COX}=$ cyclooxygenase; $\mathrm{EC}=$ endothelial cells; $\mathrm{ECE}=$ endothelin converting enzyme; $\mathrm{EDCF}=$ endothelium-derived contracting factor; $\mathrm{EDHF}=$ endothelium-derived hyperpolarizing factor; $E D R F=$ endothelium-derived relaxing factor; $E R=$ estrogen receptor; $E R E$ = estrogenresponse element; $\mathrm{ET}-1$ = endothelin-1; $\mathrm{K}^{+}$channels = potassium channels; $\mathrm{L}$-arg $=\mathrm{L}$ arginine; $\mathrm{MAPK}=$ mitogen-activated protein kinase; $\mathrm{NO}=$ nitric oxide; $\mathrm{NOS}=$ nitric oxide synthase; $\mathrm{O}_{2}^{-}=$superoxide anion; $\mathrm{pET}-1=$ prepro-endothelin-1; $\mathrm{PGF}_{2} \alpha=$ prostaglandin $\mathrm{F}_{2}$ alpha; $\mathrm{PGI}_{2}=$ prostacyclin; $\mathrm{PKC}=$ protein kinase $\mathrm{C} ; \mathrm{SMC}=$ smooth muscle cells; $\mathrm{TXA}_{2}=$ thromboxane $\mathrm{A}_{2} ; \mathrm{VOC}=$ voltage operated $\mathrm{Ca}^{2+}$ channel. 
exogenous cGMP or by stimulating cGMPdependent protein kinase activity, the authors proposed that 17ß-estradiol relaxes coronary arteries by opening $\mathrm{BKCa}$ channels via cGMP-dependent phosphorylation (55).

A direct interaction of estradiol with a voltage-gated channel subunit was described by Valverde and colleagues (56). They observed that estradiol binds to the $\beta$-subunit of maxi-K channels, which consist of a poreforming $\alpha$-subunit and a regulatory $\beta$-subunit that confers a higher $\mathrm{Ca}^{2+}$ sensitivity on the channel. Binding of estradiol to the $B$ subunit activates the maxi-K channels independent of the generation of intracellular signals and can be triggered by estradiol conjugated to a membrane-impenetrable carrier protein (56).

In contrast to the observations on smooth muscle cells, neither 17ß-estradiol nor estriol affected BKCa channel activity in human umbilical vein endothelial cells. However, 2-methoxyestradiol, an endogenous metabolite of $17 ß$-estradiol, reversibly suppressed the amplitude of $\mathrm{K}^{+}$outward currents and produced a shift in the activation curve of BKCa channels to more positive potentials. The 2-methoxyestradiol-induced inhibition of $\mathrm{BKCa}$ channels is primarily mediated by a decrease in the number of long-lived openings.

\section{Calcium channels}

Functional evidence has suggested that estrogen modulates $\mathrm{Ca}^{2+}$ entry or intracellular $\mathrm{Ca}^{2+}$ release in vascular smooth muscle cells. In rat aorta and mesenteric artery, 17ßestradiol significantly reduced the maximum contraction to norepinephrine and $\mathrm{KCl}$ without affecting potency. In experiments carried out using $\mathrm{Ca}^{2+}$-free solution in which $\mathrm{Ca}^{2+}$ stores were depleted, 17ß-estradiol significantly reduced the contraction to $\mathrm{Ca}^{2+}$ restoration in rat aorta, suggesting that $17 \beta-$ estradiol diminishes the maximum contractile response to norepinephrine due to re- striction of $\mathrm{Ca}^{2+}$ entry. Similarly, 17ß-estradiol in isolated rabbit basilar artery induced relaxation due to inhibition of extracellular $\mathrm{Ca}^{2+}$ influx to vascular smooth muscle cells, since estradiol inhibited $\mathrm{CaCl}_{2}$-induced contraction. Furthermore, basal maintained phenylephrine- and $\mathrm{KCl}$-induced [ $\left.\mathrm{Ca}^{2+}\right] \mathrm{i}$ and contraction of vascular smooth muscle triggered by $\mathrm{Ca}^{2+}$ entry from the extracellular space exhibit differences depending on the presence or absence of female gonads. Cell contraction and $\left[\mathrm{Ca}^{2+}\right]$ i due to $\mathrm{Ca}^{2+}$ release from the intracellular stores are not affected by gonadectomy. However, the observation that in the absence of extracellular $\mathrm{Ca}^{2+}, 17 ß-$ estradiol still relaxed arteries pre-contracted with norepinephrine, suggests that the hormone inhibits intracellular $\mathrm{Ca}^{2+}$ release, an effect that is possibly due to direct interactions with the cell membrane or with ion channel proteins.

Using intact and permeabilized strips and isolated single cells of smooth muscle from femoral artery and portal vein, Kitazawa et al. (57) observed that estradiol attenuated high KCl-induced force development and myosin light chain phosphorylation, and produced rapid and reversible relaxation. Estradiol also rapidly inhibited voltage-dependent L-type $\mathrm{Ca}^{2+}$ channel currents in isolated smooth muscle cells, suggesting that at pharmacological concentrations estrogen primarily reduces $\mathrm{Ca}^{2+}$ influx through inhibition of L-type $\mathrm{Ca}^{2+}$ channels and decreases myosin light chain phosphorylation and contraction of smooth muscle. 17ß-estradiol also decreased the $\left[\mathrm{Ca}^{2+}\right]$ i response to ET-1 in coronary artery smooth muscle cells isolated from gonad-intact, sexually mature female pigs, under conditions in which $\mathrm{Ca}^{2+}$ influx and sarcoplasmic reticulum $\mathrm{Ca}^{2+}$ reuptake were blocked. The effects of estradiol were blocked by extracellular lanthanum and by the specific ER antagonist ICI 182,780, indicating that estradiol decreases $\left[\mathrm{Ca}^{2+}\right] \mathrm{i}$ in coronary artery smooth muscle by affecting $\mathrm{Ca}^{2+}$ efflux via a receptor-mediated mechanism. 
By using electrophysiological techniques, Ogata and colleagues (58) demonstrated that 17ß-estradiol as well as the synthetic estrogens, ethynylestradiol and diethylstilbestrol, inhibited the barium inward current through the voltage-dependent L-type $\mathrm{Ca}^{2+}$ channel in cultured rat thoracic aortic smooth muscle cell lines (A7r5). In the rabbit basilar artery, estradiol also induces relaxation by inhibiting voltage-dependent $\mathrm{Ca}^{2+}$ channels. However, in this preparation estradiol inhibits both nicardipine-sensitive and -resistant $\mathrm{Ca}^{2+}$ currents via a pertussis toxin-sensitive GTPbinding protein.

\section{Other actions of estrogen}

Other actions of estrogen have been described such as activation of the carbon monoxide/heme oxygenase/cGMP pathway in endothelial cells of human origin (umbilical vein and uterine artery), up-regulation of $\alpha 1$ adrenergic receptors in resistance-sized mesenteric arteries and also modulation of proliferation and growth of smooth muscle cells. Looking at growth responses, it has been shown that in cultured vascular smooth muscle cells from Sprague-Dawley rats, idoxifene, a SERM, inhibited platelet-derived growth factor-induced DNA synthesis and mitogenesis and protected endothelial cells from TNF- $\alpha$-induced apoptosis in $v i$ tro. Idoxifene also modulates the balloon denudation-induced vascular injury response by significantly enhancing reendothelialization in injured carotid arteries.

\section{Cardiovascular versus global actions of estrogen}

As mentioned earlier, extensive epidemiological observations have suggested that hormone replacement therapy is associated with beneficial cardiovascular effects in postmenopausal women $(1,2)$. However, there is also evidence that hormone replacement therapy for secondary prevention of heart disease may be associated with an early increase of arterial and venous thrombotic events: 1) the heart and estrogen/progestin replacement study showed no differences in the rate of primary coronary heart disease events between active therapy and placebo after an average of 4.1 years of therapy. The study also showed an increased risk (50\%) for nonfatal myocardial infarction and coronary heart disease death during the first year of follow-up among women on active therapy; 2) in the Nurses' Health Study, women with established heart disease, but not healthy women, who had used hormone replacement therapy exhibited an increased risk of myocardial infarction recurrence or coronary heart disease death; 3) the Puget Sound Group Health Cooperative showed that healthy women on hormone replacement therapy for short periods of time had double the risk of myocardial infarction than women who had used hormone replacement therapy for longer periods (1-2 years); 4) the Women's Health Initiative trial also showed, two years ago, a trend toward early increased cardiovascular risk in healthy women, and very recently this trial was interrupted due to a recommendation from the Data and Safety Monitoring Board. The reason was that the test statistic for invasive breast cancer exceeded the stopping boundary for this adverse effect and the global index statistics supported risks exceeding benefits among healthy postmenopausal women. The results indicated that the hormone replacement regimen in the Women's Health Initiative trial should not be initiated or continued for primary prevention of coronary heart disease (59).

However, the reasons for this lack of benefit are not yet clear and differ from the beneficial effects predicted in observational studies and in animal models of cardiovascular disease. Dose regimen, combination of estrogen with progestins versus estrogen alone, the administration route and duration of treatment are some of the factors that may be involved in the discrepancies. The pres- 
ence of gene polymorphisms in the setting of estrogen therapy has also been implicated as one possible reason for the disappointing results. Polymorphisms in genes related to thrombotic events, such as factor V Leiden, prothrombin, factor VII, fibrinogen and plasma activator inhibitor I, could increase the risk for cardiovascular disease and thrombotic complications in a subset of women and, therefore, would obscure the real benefit of estrogen replacement therapy (60). If this is the case, estrogen replacement therapy may be useful to prevent cardiovascular disease in a large number of postmenopausal women, but not in a subset of women who are at high risk for cardiovascular and thrombotic complications (60).

\section{Conclusions}

Estrogen is active both in vascular smooth muscle and endothelial cells and may exert its cardiovascular protective actions by a direct effect on the vessel wall. Clinical and animal studies have demonstrated the beneficial effects of estrogen on the vascular system. However, because estrogen affects so many cellular processes, it is imperative to gain a better understanding of the molecular mechanisms, both genomic and nongenomic, by which estrogen induces cellular signals and modulates vascular responses. Furthermore, the beneficial clinical effects of estrogen need to be confirmed in large and multicenter randomized clinical trials.

\section{References}

1. Barret-Connor E \& Bush TL (1991). Estrogen and coronary heart disease in women. Journal of the American Medical Association, 265: 1861-1867.

2. Kanel WB, Hjortland MC, McNamara PM \& Gordon T (1976). Menopause and risk of cardiovascular disease: the Framingham study. Annals of Internal Medicine, 85: 447-452.

3. Beato M \& Sanchez-Pacheco A (1996). Interaction of steroid hormone receptors with the transcription initiation complex. Endocrine Reviews, 17: 587-609.

4. Russell KS, Haynes MP, Sinha D, Clerisme E \& Bender JR (2000). Human vascular endothelial cells contain membrane binding sites for estradiol, which mediate rapid intracellular signaling. Proceedings of the National Academy of Sciences, USA, 97: 5930-5935.

5. Kelly MJ \& Levin ER (2001). Rapid actions of plasma membrane estrogen receptors. Trends in Endocrinology and Metabolism, 12: 152-156.

6. Simoncini T, Hafezi-Moghadam A, Brazil DP, Ley K, Chin WW \& Liao JK (2000). Interaction of oestrogen receptor with the regulatory subunit of phosphatidylinositol-OH kinase. Nature, 407: 538-541.

7. Green $S$, Walter $P$, Kumar V, Krust A, Bornert JM, Argos P \& Chambon P (1986). Human oestrogen receptor cDNA sequence, expression and homology to v-erb-A. Nature, 320: 134-139.

8. Greene GL, Gilna P, Waterfield M, Baker A, Hoter $Y$ \& Shine J (1986). Sequence and expression of human estrogen receptor complementary DNA. Science, 231: 1150-1154.

9. Kuiper GGJM, Enmark E, Pelto-Huikko M, Nilsson S \& Gustafsson JA (1996). Cloning of a novel estrogen receptor expressed in rat prostate and ovary. Proceedings of the National Academy of Sciences, USA, 93: 5925-5930.

10. Paech K, Webb P, Kuiper GG, Nilsson S, Gustafsson J, Kushner PJ \& Scanlan TS (1997). Differential ligand activation of estrogen receptors ER $\alpha$ and ERß at AP1 sites. Science, 277: 1508-1510.

11. Korach KS (1994). Insights from the study of animals lacking functional estrogen receptor. Science, 266: 1524-1527.
12. Krege JH, Hodgin JB, Couse JF, Enmark E, Warner M, Mahler JF, Sar M, Korach KS, Gustafsson JA \& Smithies O (1998). Generation and reproductive phenotypes of mice lacking estrogen receptor $ß$. Proceedings of the National Academy of Sciences, USA, 95: 1567715682.

13. Harada N, Sasano $H$, Murakami $H$, Ohkuma $T$, Nagura $H$ \& Takagi $Y$ (1999). Localized expression of aromatase in human vascular tissues. Circulation Research, 84: 1285-1291.

14. Zhu Y, Bian Z, Lu P et al. (2002). Abnormal vascular function and hypertension in mice deficient in estrogen receptor beta. Science, 295: 505-508

15. Hayashi T, Fukuto JM, Ignarro LJ \& Chaudhuri G (1992). Basal release of nitric oxide from aortic rings is greater in female rabbits than male rabbits: implications for atherosclerosis. Proceedings of the National Academy of Sciences, USA, 89: 11259-11263.

16. Nigro D, Fortes ZB, Scivoletto R \& Carvalho MHC (1990). Simultaneous release of endothelium-derived relaxing and contracting factors induced by noradrenaline in normotensive rats. General Pharmacology, 21: 443-446.

17. Huang A, Sun D, Koller A \& Kaley G (2000). 17beta-estradiol restores endothelial nitric oxide release to shear stress in arterioles of male hypertensive rats. Circulation, 101: 94-100.

18. Caulin-Glaser T, Garcia-Cardena G, Sarrel P, Sessa WC \& Bender JR (1997). 17ß-Estradiol regulation of human endothelial cell basal nitric oxide release, independent of cytosolic $\mathrm{Ca}^{2+}$ mobilization. Circulation Research, 81: 885-892.

19. Chen Z, Yuhanna IS, Galcheva-Gargova Z, Karas RH, Mendelsohn ME \& Shaul PW (1999). Estrogen receptor alpha mediates the nongenomic activation of endothelial nitric oxide synthase by estrogen. Journal of Clinical Investigation, 103: 401-406.

20. Costa SG, Anversa P, Scavone C, Sucupira M \& Carvalho MHC (1998). Nitric oxide synthase activity in microvessels of SHR and normotensive rats: effects of estrogen. Journal of Hypertension, 25: S80 (Abstract). 
21. Hisamoto K, Ohmichi M, Kurachi H et al. (2001). Estrogen induces the Akt-dependent activation of endothelial nitric-oxide synthase in vascular endothelial cells. Journal of Biological Chemistry, 276: 3459-3467.

22. Jayachandran M, Hayashi T, Sumi D, Iguchi A \& Miller VM (2001). Temporal effects of 17beta-estradiol on caveolin-1 mRNA and protein in bovine aortic endothelial cells. American Journal of Physiology, 281: H1327-H1333.

23. Simoncini T, Genazzani AR \& Liao JK (2002). Nongenomic mechanisms of endothelial nitric oxide synthase activation by the selective estrogen receptor modulator raloxifene. Circulation, 105: 1368-1373.

24. Tolbert T, Thompson JA, Bouchard P \& Oparil S (2001). Estrogeninduced vasoprotection is independent of inducible nitric oxide synthase expression: evidence from the mouse carotid artery ligation model. Circulation, 104: 2740-2745.

25. Harder DR \& Coulson PB (1979). Estrogen receptors and effects of estrogen on membrane electrical properties of coronary vascular smooth muscle. Journal of Cell Physiology, 100: 375-382.

26. Sakuma I, Liu MY, Sato A, Hayashi T, Iguchi A, Kitabatake A \& Hattori $Y$ (2002). Endothelium-dependent hyperpolarization and relaxation in mesenteric arteries of middle-aged rats: influence of oestrogen. British Journal of Pharmacology, 135: 48-54.

27. Ospina JA, Krause DN \& Duckles SP (2002). 17beta-estradiol increases rat cerebrovascular prostacyclin synthesis by elevating cyclooxygenase-1 and prostacyclin synthase. Stroke, 33: 600-605.

28. Akarasereenont $P$, Techatraisak K, Thaworn A \& Chotewuttakorn S (2000). The induction of cyclooxygenase-2 by 17beta-estradiol in endothelial cells is mediated through protein kinase C. Inflammation Research, 49: 460-465.

29. Calkin AC, Sudhir K, Honisett S, Williams MR, Dawood T \& Komesaroff PA (2002). Rapid potentiation of endothelium-dependent vasodilation by estradiol in postmenopausal women is mediated via cyclooxygenase 2. Journal of Clinical Endocrinology and Metabolism, 87: 5072-5075.

30. Dantas AP, Scivoletto R, Fortes ZB, Nigro D \& Carvalho MH (1999). Influence of female sex hormones on endothelium-derived vasoconstrictor prostanoid generation in microvessels of spontaneously hypertensive rats. Hypertension, 34 (Part 2): 914-919.

31. Koh KK, Son JW, Ahn JY, Lee SK, Hwang HY, Kim DS, Jin DK, Ahn TH \& Shin EK (2001). Effect of hormone replacement therapy on nitric oxide bioactivity and monocyte chemoattractant protein-1 levels. International Journal of Cardiology, 81: 43-50.

32. Cid MC, Kleinman HK, Grant DS, Schnaper HW, Fauci AS \& Hoffman GS (1994). Estradiol enhances leukocyte binding to tumor necrosis factor (TNF)-stimulated endothelial cells via an increase in TNFinduced adhesion molecules E-selectin, intercellular adhesion molecule type 1 and vascular cell adhesion molecule type 1. Journal of Clinical Investigation, 93: 17-25.

33. Caulin-Glaser T, Watson CA, Pardi R \& Bender JR (1996). Effects of $17 ß$-estradiol on cytokine-induced endothelial cell adhesion molecule expression. Journal of Clinical Investigation, 98: 36-42.

34. Wagner AH, Schroeter MR \& Hecker M (2001). 17beta-estradiol inhibition of NADPH oxidase expression in human endothelial cells. FASEB Journal, 15: 2121-2130.

35. Barbacanne MA, Rami J, Michel JB, Souchard JP, Philippe M, Besombes JP, Bayard F \& Arnal JF (1999). Estradiol increases rat aorta endothelium-derived relaxing factor (EDRF) activity without changes in endothelial NO synthase gene expression: possible role of decreased endothelium-derived superoxide anion production. Cardiovascular Research, 41: 672-681.

36. Wassmann S, Baumer AT, Strehlow K, van Eickels M, Grohe C,
Albory K, Rosen R, Bohm M \& Nickenig G (2001). Endothelial dysfunction and oxidative stress during estrogen deficiency in spontaneously hypertensive rats. Circulation, 103: 435-441.

37. Gragasin FS, Xu Y, Arenas IA, Kainth N \& Davidge ST (2003). Estrogen reduces angiotensin II-induced nitric oxide synthase and $\mathrm{NAD}(\mathrm{P}) \mathrm{H}$ oxidase expression in endothelial cells. Arteriosclerosis, Thrombosis, and Vascular Biology, 23: 38-44.

38. Dantas AP, Tostes RC, Fortes ZB, Costa SG, Nigro D \& Carvalho MH (2002). In vivo evidence for antioxidant potential of estrogen in microvessels of female spontaneously hypertensive rats. Hypertension, 39 (Part 2): 405-411.

39. Virdis A, Ghiadoni L, Pinto S, Lombardo M, Petraglia F, Gennazzani A, Buralli S, Taddei S \& Salvetti A (2000). Mechanisms responsible for endothelial dysfunction associated with acute estrogen deprivation in normotensive women. Circulation, 101: 2258-2263.

40. Nickenig G, Strehlow K, Wassmann S, Baumer AT, Albory K, Sauer $H$ \& Bohm M (2000). Differential effects of estrogen and progesterone on $A T(1)$ receptor gene expression in vascular smooth muscle cells. Circulation, 102: 1828-1833.

41. Takeda-Matsubara $Y$, Nakagami H, Iwai M, Cui TX, Shiuchi T, Akishita M, Nahmias C, Ito M \& Horiuchi M (2002). Estrogen activates phosphatases and antagonizes growth-promoting effect of angiotensin II. Hypertension, 39: 41-45.

42. Brosnihan KB, Senanayake PS, Li P \& Ferrario CM (1999). Bi-directional actions of estrogen on the renin-angiotensin system. Brazilian Journal of Medical and Biological Research, 32: 373-381.

43. Nigro D, Fortes ZB, Scivoletto R, Barbeiro HV \& Carvalho $\mathrm{MH}$ (1997). Sex-related differences in the response of spontaneously hypertensive rats to angiotensin-converting enzyme inhibitor. Endothelium, 5: 63-71.

44. Silva-Antonialli MM, Fortes ZB, Carvalho MH, Scivoletto R \& Nigro $D$ (2000). Sexual dimorphism in the response of thoracic aorta from SHRs to losartan. General Pharmacology, 34: 329-335.

45. Barber DA, Michener SR, Ziesmer SC \& Miller VM (1996). Chronic increases in blood flow upregulate endothelin-B receptors in arterial smooth muscle. American Journal of Physiology, 270: H65-H71.

46. Ergul A, Shoemaker K, Puett D \& Tackett RL (1998). Gender differences in the expression of endothelin receptors in human saphenous vein in vitro. Journal of Pharmacology and Experimental Therapeutics, 285: 511-517.

47. Tostes RCA, David FL, Carvalho MHC, Nigro D, Scivoletto R \& Fortes ZB (2000). Gender differences in vascular reactivity to endothelin-1 in deoxycorticosterone acetate-salt hypertensive rats. Journal of Cardiovascular Pharmacology, 35 (Suppl 6): S99-S101.

48. Tostes RCA, David FL, Fortes ZB, Nigro D, Scivoletto R \& Carvalho MHC (2000). Deoxycorticosterone acetate-salt hypertensive rats display gender-related differences in ETB receptor-mediated vascular responses. British Journal of Pharmacology, 130: 1092-1098.

49. David FL, Carvalho MH, Cobra AL, Nigro D, Fortes ZB, Rebouças NA \& Tostes RC (2001). Ovarian hormones modulate endothelin-1 vascular reactivity and mRNA expression in DOCA-salt hypertensive rats. Hypertension, 38 (Part 2): 692-696.

50. David FL, Montezano ACl, Rebouças NA, Nigro D, Fortes ZB, Carvalho MHC \& Tostes RC (2002). Gender differences in vascular expression of endothelin and ET A/ET B receptors, but not in calcium handling mechanisms, in deoxycorticosterone acetate-salt hypertension. Brazilian Journal of Medical and Biological Research, 35: 1061-1068.

51. Fortes ZB, Nigro D, Scivoletto R \& Carvalho MH (1991). Influence of sex on the reactivity to endothelin-1 and noradrenaline in spontaneously hypertensive rats. Clinical and Experimental Hypertension. 
Part A, Theory and Practice, 13: 807-816.

52. Dubey RK, Jackson EK, Keller PJ, Imthurn B \& Rosselli M (2001). Estradiol metabolites inhibit endothelin synthesis by an estrogen receptor-independent mechanism. Hypertension, 37 (Part 2): 640644.

53. Saitta A, Altavilla D, Cucinotta D et al. (2001). Randomized, doubleblind, placebo-controlled study on effects of raloxifene and hormone replacement therapy on plasma NO concentrations, endothelin-1 levels, and endothelium-dependent vasodilation in postmenopausal women. Arteriosclerosis, Thrombosis, and Vascular Biology, 21: 1512-1519.

54. Martinez C, Sanchez M, Hidalgo A \& Garcia de Boto MJ (2001). Involvement of K(ATP) channels in diethylstilbestrol-induced relaxation in rat aorta. European Journal of Pharmacology, 413: 109-116.

55. White RE, Darkow DJ \& Lang JL (1995). Estrogen relaxes coronary arteries by opening BKCa channels through a cGMP-dependent mechanism. Circulation Research, 77: 936-942.

56. Valverde MA, Rojas P, Amigo J, Cosmelli D, Orio P, Bahamonde MI,
Mann GE, Vergara C \& Latorre R (1999). Acute activation of Maxi-K channels (hSlo) by estradiol binding to the beta subunit. Science, 285: 1929-1931.

57. Kitazawa T, Hamada E, Kitazawa K \& Gaznabi AK (1997). Nongenomic mechanism of 17 beta-oestradiol-induced inhibition of contraction in mammalian vascular smooth muscle. Journal of Physiology, 499 (Part 2): 497-511.

58. Ogata R, Inoue $Y$, Nakano H, Ito $Y$ \& Kitamura K (1996). Oestradiolinduced relaxation of rabbit basilar artery by inhibition of voltagedependent Ca channels through GTP-binding protein. British Journal of Pharmacology, 117: 351-359.

59. Writing Group for the Women's Health Initiative Investigators (2002). Risks and benefits of estrogen plus progestin in healthy postmenopausal women. Journal of the American Medical Association, 288: 321-333

60. Herrington DM \& Klein KP (2001). Pharmacogenetics of estrogen replacement therapy. Journal of Applied Physiology, 91: 2776-2784. 